\title{
Finite element analysis comparing WaveOne Gold and ProTaper Next endodontic file segments subjected to bending and torsional load
}

\author{
Amira Galal Ismail ${ }^{*}$ D, Mohamed Hussein Abdelfattah Zaazou, Manar Galal, Nada Omar Mostafa Kamel and
} Mohamed Abdulla Nassar

\begin{abstract}
Background: The objective of this study was to assess the bending and torsional properties of two nickel-titanium endodontic files with equivalent sizes and various designs and alloys using finite element analysis, ProTaper Next ${ }^{\oplus}$ 2 (PTN) size 25 with 0.06 taper and WaveOne Gold ${ }^{\circledR}$ (WOG) primary size 25 with 0.07 taper.

Methodology: Two-dimensional models of the two files PTN and WOG were created using computer tomography scanning and stereomicroscope to produce a three-dimensional digital model. Instrument behavior under bending or torsional conditions was numerically analyzed in SolidWorks software package.

Result: ProTaper Next ${ }^{\oplus}$ revealed higher flexibility than WaveOne Gold ${ }^{\circledR}$ when exposed to cantilever bending but showed higher stress accumulation than WOG. In terms of torsional resistance, PTN also revealed higher torsional resistance than WOG.

Conclusion: The geometry of the instrument, thermomechanical treatment of the alloy, and its composition affect the mechanical behavior (bending and torsion) of nickel titanium rotary files. Hence, being aware of these behavioral differences, each clinician will be able to use the adequate file according to the clinical situation in addition to the manufacturer's instructions.
\end{abstract}

Keywords: WaveOne Gold, ProTaper Next, M-wire, Gold alloy, Cross section, Torsion, Cyclic fatigue, Finite element

\section{Introduction}

Recently, there have been significant enhancements in the design and alloy of NiTi rotary files by improving the process of manufacturing, properties of the materials, and its microstructures (Gao et al. 2012; Elnaghy 2014; Braga et al. 2013; Lopes et al. 2013). Inspite of the increased flexibility in comparison with the stainless steel files, NiTi rotary instruments are more prone to fracture (Iqbal et al. 2006). Several studies revealed that the rate of fracture of $\mathrm{NiTi}$ is seven times more than stainless steel files while others reported that NiTi rotary files fractured at a rate of approximately 5 times clinically (Alapati et al. 2005).

\footnotetext{
* Correspondence: amirgalal@gmail.com

Restorative and Dental Material Department, National Research Centre, Cairo, Egypt
}

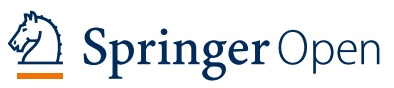

Many factors may relate to file separation, but cyclic fatigue and torsional stress are the two main causes (AlHadlaq et al. 2010; Park et al. 2010). Cyclic fatigue is common in curved canals where the file is exposed to repetitive compression and tension (Al-Hadlaq et al. 2010). Torsional failure is prevalent in narrow straight canals where the tip of the file is locked in the canal while the shank continues to rotate (Park et al. 2010). Flexible files will decrease iatrogenic errors as canal transportation and will lead to a more centered and safer preparation. Heat treatment and composition of the alloy, in addition to instrument geometry, influence the flexibility of NiTi rotary files. Thermal modification of the alloy results in alteration of the physical properties (Ha et al. 2013; Goo et al. 2017). 
ProTaper Next ( Dentsply Sirona, Ballaigues, Switzerland) is made of $\mathrm{M}$-wire premanufacturing heat treatment technology with a rectangular asymmetric cross section, variable taper and is run by a clockwise (CW) continuous rotation. M-wire has resulted in an increased resistance of the file to cyclic fatigue of up to $400 \%$ compared to other files (Dentsply Maillefer n.d.; Topçuoğlu et al. 2017). Moreover, this asymmetric cross section improves canal shaping effectiveness as assumed by manufacturer (Elnaghy 2014).

WaveOne Gold (Dentsply Maillefer) when introduced was claimed to have an increased elasticity owing to its metallurgical developments in gold-wire heat treatment. The gold process is a post-manufacturing procedure in which the ground NiTi files are heat-treated and slowly cooled. Its parallelogram-shaped cross-section has two cutting edges which are in contact with the canal wall, alternating with an off-centered cross section where only one cutting edge contacts the canal wall. It rotates in a reciprocal motion, with preset values set by the manufacturer of clockwise/counter clockwise angles. Counterclockwise which is greater than the clockwise allows the file to progress apically while the latter disengages the file and eliminates file binding (Webber 2016; Adıgüzel and Capar 2017).

Interpreting all the mechanical properties of those recent NiTi rotary files and how it affect their performance in the canal is very important in order to select the adequate file according to each clinical situation. Therefore, the aim of this study was to compare the mechanical properties of the PTN files with WOG.

\section{Materials and methods}

\section{Endodontic instrument analyzed}

Two NiTi instruments with similar cross-sectional geometry but different alloys were selected for this study; PTN X2 $(25,0.06)$ variable taper with a rectangular cross section. It has a centered mass and axis of rotation from D1-D3 (diameter), whereas from D4-D16 has an offset mass of rotation. Starting at $6 \%$, the X2 file has ten increasing percentage tapers from D1-D11, whereas from D12-D16, there are decreasing percentage tapers.

WOG Primary $(25,0.07)$ variable taper with a parallelogram cross section with two cutting edges in contact with the canal wall, alternating with an off-centered cross section. WOG has a fixed taper from D1-D3, yet a

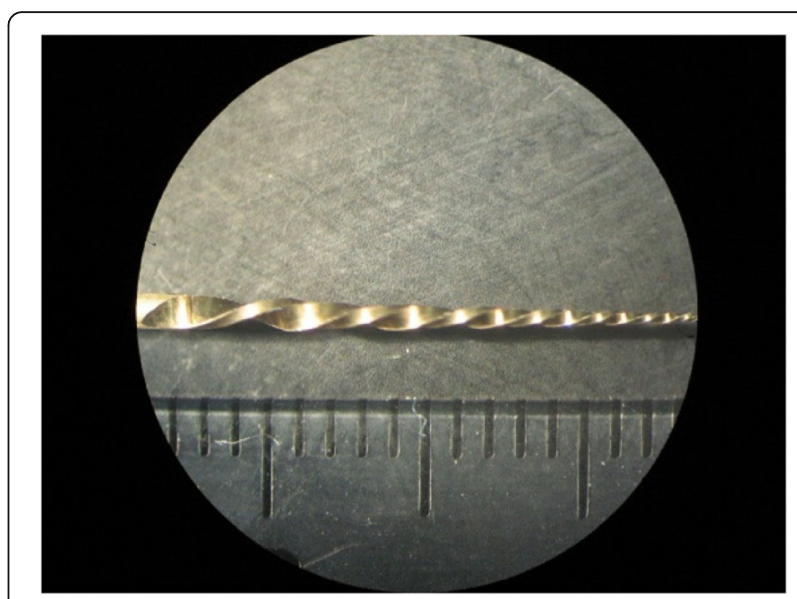

Fig. 1 Stereomicroscope imaging of WaveOne Gold

progressively decreasing percentage tapered design from D4-D16, the primary file has diameters of $0.85 \mathrm{~mm}$ and $1.0 \mathrm{~mm}$ at $\mathrm{D} 9$ and $\mathrm{D} 12$, respectively.

\section{Finite element analysis Image processing}

Image processing was done using computer tomography and stereomicroscope scanning to obtain a 3D image. WaveOne Gold ${ }^{\circ}$ and ProTaper Next ${ }^{\circ}$ were both imaged at X5, X10, and X16 magnifications to obtain a detailed shape to obtain an accurate measurement of the files (Galal et al. 2015) (Fig. 1).

\section{Construction of 3D model}

Classic modeling using CAD programs To build the file's model, the file cross section, rectangular for PTN, and parallelogram for WOG were drawn in 2D using computer-aided design programs (CAD) (SolidWorks software package). The 2D file with (.prt) extension was converted into Stereolithographic (.stl) extension to be readable by programming software (MATLAB software) (Galal et al. 2015).

3D modeling using MATLAB software Building of 3D model in the form of sections was performed by MATLAB software using the following data: taper of the file, change in

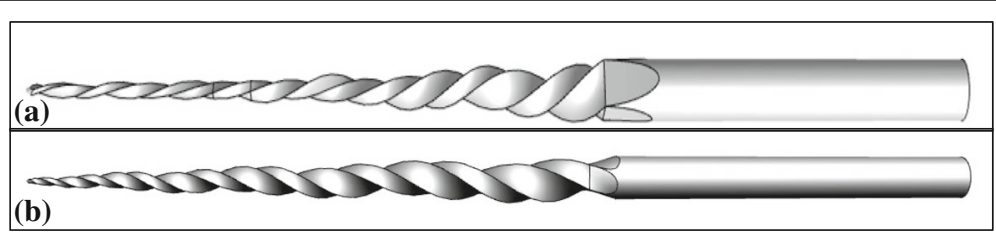

Fig. 2 3D model diagram. a ProTaper Next. b WaveOne Gold 


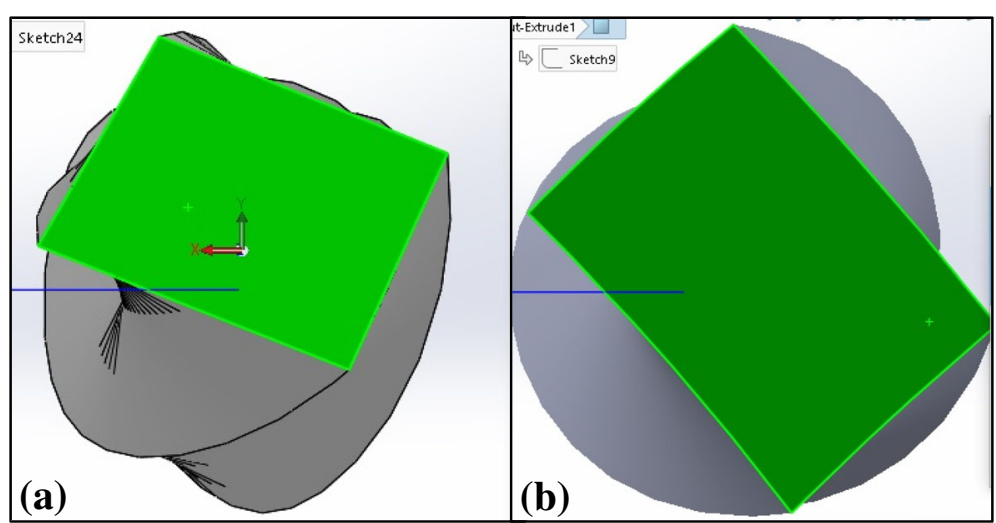

Fig. 3 Cross-section design of the file's 3D model diagram. a ProTaper Next. b WaveOne Gold

pitch length, and cross-section changes (Galal et al. 2015) (Figs. 2a, b, 3a, b).

Creation of finite element models Using CAD (SolidWorks software package), finite element (FE) models for each file were created. The meshing of the models was done by (SolidWorks software package) using nonlinear static analysis type. The final FE model of PTN file consisted of 3236 elements with 5828 nodes, and for WOG consisted of 4847 nodes and 2607 elements. For PTN, the maximum element size was 0.509905, while the minimum element size was $0.101981 \mathrm{~mm}$, and for WOG the maximum element size was 0.541989, while the minimum element size was $0.108398 \mathrm{~mm}$. The stress strain behavior was obtained from the literature and entered in the SolidWorks software package (Fig. 4a, b).

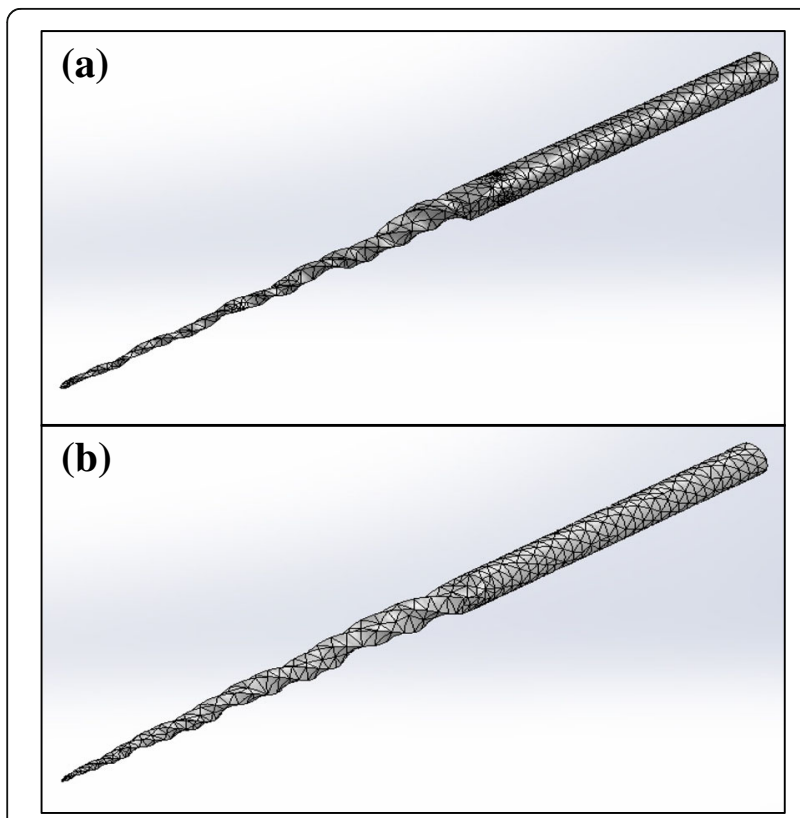

Fig. 4 Meshing of 3D models. a ProTaper Next. b WaveOne Gold

\section{Mathematical analysis of FE models}

The mathematical analysis of the two finite element models was performed on SolidWorks software package. The mechanical behavior of the NiTi files was analyzed numerically in a SolidWorks package to simulate and measure bending and torsion (Galal et al. 2015).

Application of bending Cantilever bending was simulated for the FE models by applying a constant load of 1 $\mathrm{N}$ at the tip of the file with its shaft rigidly held in place. The vertical displacement was measured and the von Mises stress distribution was evaluated (Kim et al. 2009).

Application of shear moment (torsion) Application of a shear moment (torsion) $2.5 \mathrm{~N} / \mathrm{mm}$ moment of force was applied to the shaft in a clockwise direction, while the last $4 \mathrm{~mm}$ of the tip was rigidly constrained. The stress distribution was evaluated (Kim et al. 2009).

\section{Results}

Bending resistance test

A maximum von Mises stress of $923 \mathrm{MPa}$ appeared in the ProTaper $\mathrm{Next}^{\circ}$ file with $11 \mathrm{~mm}$ displacement. The highest stress appeared near the middle one third of the shaft. A maximum von Mises stress of $846.5 \mathrm{MPa}$ appeared in WaveOne Gold ${ }^{\oplus}$ file. The highest stress appeared near the tip of shaft where the file was fixed and decreased as it moved away from the supporting point (Table 1), (Fig. 5a, b).

Table 1 Maximum Von Mises stress during bending resistance test of different files

\begin{tabular}{lll}
\hline Bending at $1 \mathrm{~N}$ & WaveOne Gold & ProTaper Next \\
\hline Deflection $(\mathrm{mm})$ & 8.045 & 11 \\
Maximum stress $(\mathrm{MPa})$ & 846.5 & 923 \\
\hline
\end{tabular}




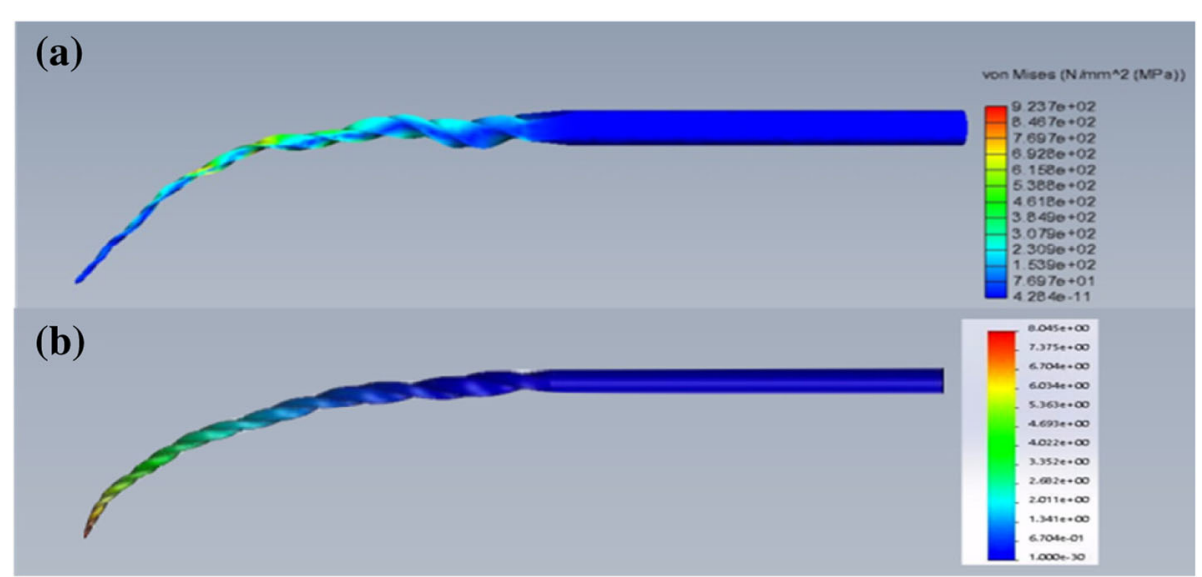

Fig. 5 Finite element model of the stress distribution during bending. a ProTaper Next. b WaveOne Gold

\section{Torsion resistance test}

A maximum von Mises stress of $608 \mathrm{MPa}$ appeared in the ProTaper $\mathrm{Next}^{\bullet}$ file. The highest stress appeared near the tip of the shaft and decreased towards the middle. A maximum von Mises stress of $1475 \mathrm{MPa}$ appeared in WaveOne Gold $^{\circledR}$ file. The highest stress was limited to the tip of shaft (Table 2) (Fig. 6a, b).

\section{Discussion}

This study assessed, compared, and analyzed the flexibility, torsion resistance, and stress distribution patterns of PTN and WOG via finite element analysis. Finite element analysis (FEA) is a numerical procedure capable of evaluating and assessing the mechanical behavior of the instrument in addition to the stress distribution during root canal treatment. The value of FEA is a welldocumented procedure in endodontic research. In a virtual environment, the FEA method consists of modeling a structure with loads and boundaries to specify, analyze, and solve potential structural or performance issues. In simulations of finite element analysis, a structure is idealized as many small, discrete segments known as finite elements connected at nodes. The resulting models include salient features, such as materials, geometrical characteristics, boundary conditions, and loads in order to reveal reality as close as possible (Kim et al. 2009; Wakabayashi et al. 2008).

The main advantage of FEA simulation methods is that different characteristics such as different alloys or designs can be nondestructively applied. The amount of deflection under cantilever bending is a measure of instrument flexibility. Flexibility of NiTi rotary instruments is a significant factor because it is responsible of the mechanical behavior and performance of files in curved canals (Ha et al. 2017).

PTN revealed a greater deflection than WOG indicating that PTN possesses higher flexibility. Both PTN and WOG have an off-centered cross-sectional design which reduces the screw in force and both are subjected to heat treatment (Ha et al. 2017).

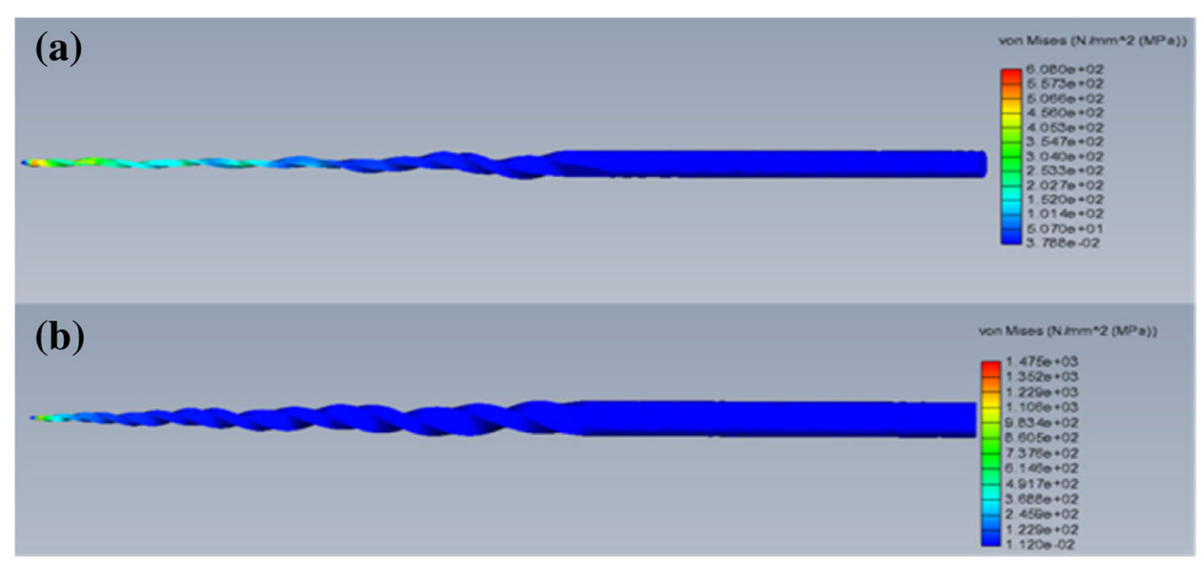

Fig. 6 Finite element model of the stress distribution during torsion. a ProTaper Next. b WaveOne Gold 
Table 2 Maximum Von Mises stress during torsion resistance test of different files

\begin{tabular}{lll}
\hline Torsional moment at $2.5 \mathrm{~N} / \mathrm{mm}$ & WaveOne Gold & ProTaper Next \\
\hline Maximum stress (MPa) & 1475 & 608 \\
\hline
\end{tabular}

The M-wire NiTi from which PTN is manufactured is exposed to thermo-mechanical processing which results in increased flexibility, leading to a better access and preparation of curved canals. M-wire contains austenite phase with little amounts of martensite and R-phase at body temperature, hence $\mathrm{M}$-wire maintains superelastic state (Zupanc et al. 2018).

The highest stress of PTN file appeared near the middle one third of the shaft, and this may be related to the increasing taper which is $7 \%$ from $6-9 \mathrm{~mm}$ and then it decreases to $6 \%$.

WOG incorporates a new NiTi alloy which has undergone a thermomechanical treatment. However, it is important to point out several other factors that would have considerable influence on fatigue behavior and stress distribution of NiTi including cross-sectional area and helical angle. WOG has a parallelogram cross section vs a rectangular cross-sectional design of PTN. According to the numerical values if FEA, PTN has a smaller area than WOG which renders it more flexible. Moreover, Siva et al. (Silva et al. 2016) found more machining defects in WOG compared to Reciproc upon SEM evaluation. These defects may negatively influence the cyclic fatigue resistance. Highest stress of WOG file was concentrated at the tip and decreased as it moved away from the point of support. This may be due to the decreasing taper of the file which $7 \%$ at the 1 st $3 \mathrm{~mm}$ and decreases to $6 \%$.

WOG revealed slight less concentration of stress than PTN. This was in accordance with Siva et al. which revealed that all gold heat-treated files revealed enhanced flexibility and fatigue resistance compared with M-wire instruments (Silva et al. 2016).

As reported by Ninan \& Berzins, file size and torsional resistance are directly related. Likewise, the greater taper instruments reveal greater torque but less angle of rotation. Hence, comparison between instruments was done from this perspective (Ninan and Berzins 2013).

WOG Primary and PTN both have a tip size of 25 with a 0.07 and 0.06 taper, respectively, which is constant in the apical $3 \mathrm{~mm}$ of the instruments. Therefore, the greater apical taper of WOG led to higher torsional than the PTN regardless the thermal treatment of the alloy. Stress concentration in PTN was concentrated near the tip and along the middle third due to increased taper and in WOG stress concentration decreased away from the tip due to decrease in taper.

\section{Conclusion}

Under the conditions of this experiment, ProTaper Next revealed both higher flexibility and torsional resistance than WaveOne Gold which reflects that the behavior of instruments mechanically depends not only on the thermomechanical treatment of the alloy but also on other factors such as instrument design and taper.

\section{Abbreviations \\ CAD: Computer-aided design; CCW: Counter clockwise; CW: Clockwise; FE: Finite element; FEA: Finite element analysis; NiTi: Nickel titanium; PTN: ProTaper Next; WOG: WaveOne Gold}

\section{Acknowledgements}

Not applicable.

\section{Authors' contributions}

AGI wrote manuscript and analyzed the data. MHZ substansively revised the work. MG analyzed data and interpreted it. NO analyzed the data and interpreted it. MAN performed the measurements. All authors read and approved the final manuscript.

\section{Authors' information}

Dr. Amira Galal is a graduate (2001) and postgraduate (Msc-2009, phD2015) of Cairo University, School of Oral and Dental Medicine. She is currently a Researcher of Endodontics at the National Research Centre and a part time Lecturer of Endodontics at Misr International University. Dr Amira is also an FDI speaker and has lectured extensively nationally and internationally. Moreover, she has published articles in local and international Journals. Dr Amira operates at her own private practice "Dr Amira Galal Dental Care" in New Cairo, Egypt.

\section{Funding}

Funded by the National Research Centre.

\section{Availability of data and materials}

The datasets used and/or analyzed during the current study are available from the corresponding author on reasonable request. All data generated or analyzed during this study are included in this published article.

Ethics approval and consent to participate

Not applicable.

\section{Consent for publication}

Not applicable.

\section{Competing interests}

The authors declare that they have no competing interests.

Received: 23 August 2019 Accepted: 18 October 2019

Published online: 19 December 2019

\section{References}

Adıgüzel M, Capar ID (2017) Comparison of cyclic fatigue resistance of WaveOne and WaveOne Gold small, primary, and large instruments. J Endod 43(4):623-627

Alapati SB, Brantley WA, Svec TA, Powers JM, Nusstein JM, Daehn GS (2005) SEM observations of nickel-titanium rotary endodontic instruments that fractured during clinical use. J Endod 31(1):40-43

Al-Hadlaq SM, Aljarbou FA, Al Thumairy RI (2010) Evaluation of cyclic flexural fatigue of M-wire nickel-titanium rotary instruments. J Endod 36:305-307

Braga LC, Magalhaes RR, Nakagawa RK (2013) Physical and mechanical properties of twisted or ground nickel-titanium instruments. Int Endod J 46:458-465

Dentsply Maillefer (n.d.). The ProTaper Next Brochure. Available at: http://www. dentsplymaillefer.com/\#/218x624/218x7718/line_218x7727/product_218x91 05/. Accessed 10 Jan 2014.

Elnaghy AM (2014) Cyclic fatigue resistance of ProTaper Next nickel-titanium rotary files. Int Endod J 6. https://doi.org/10.1111/iej.12244 [Epub ahead of print] 
Galal M, Nassef T, Saber S, Zaazou M, El-Ashry S (2015) Stress distribution of three NiTi rotary files under bending and torsional conditions using a finite element analysis. Ain Shams Med J

Gao Y, Gutmann JL, Wilkinson K (2012) Evaluation of the impact of raw materials on the fatigue and mechanical properties of ProFile Vortex rotary instruments. J Endod 38:398-401

Goo HJ, Kwak SW, Ha JH, Pedullà E, Kim HC (2017) Mechanical properties of various heat-resistance treated nickel-titanium rotary instruments. J. Endod 43:1872-1877

Ha JH, Kim SK, Cohenca N, Kim HC (2013) Effect of R-phase heat treatment on torsional resistance and cyclic fatigue fracture. J Endod 39:389-393

Ha J-H, Kwak SW, Versluis A, Lee C-J, Park S-H, Kim H-C (2017) The geometric effect of an off-centered cross-section on nickel-titanium rotary instruments: a finite element analysis study. J Dent Sci 12(2):173-178

Iqbal MK, Kohli MR, Kim JS (2006) A retrospective clinical study of incidence of root canal instrument separation in an endodontics graduate program: a Penn Endo database study. J Endod 32:1048-1052

Kim TO, Cheung GSP, Lee JM, Kim BM, Hur B, Kim HC (2009) Stress distribution of three NiTi rotary files under bending and torsional conditions using a mathematic analysis. Int Endod J 42:14-21

Lopes HP, Gambarra-Soares T, Elias CN (2013) Comparison of the mechanical properties of rotary instruments made of conventional nickel-titanium wire, M-wire, or nickel-titanium alloy in R-phase. J Endod 39:516-520

Ninan E, Berzins DW (2013) Torsion and bending properties of shape memory and superelastic nickel-titanium rotary instruments. J Endod 39(1):101-104

Park SY, Cheung GS, Yum J et al (2010) Dynamic torsional resistance of nickeltitanium rotary instruments. J Endod 36:1200-1204

Silva EJNL, Tinoco JM, Tinoco EMB, Vieira VTL, Sassone LM, Lopes HP (2016) Bending resistance and cyclic fatigue life of a new single-file reciprocating instrument WaveOne Gold. Eur Endod J 1(1):4

Topçuoğlu HS, Düzgün S, Akti A, Topçuoglu G (2017) Laboratory comparison of cyclic fatigue of WaveOne Gold, Reciproc and WaveOne files in canals with a double curve. Int Endod J 50:713-717

Wakabayashi N, Ona M, Suzuki T, Igarashi Y (2008) Nonlinear finite element analyses: advances and challenges in dental applications. J Dent 36(7):463-471

Webber J (2016) Shaping canal with confidence: WaveOne Gold single file, a system. Int Dent Afr Ed 6(3):6-17

Zupanc J, Vahdat-Pajouh N, Schäfer E (2018) New thermomechanically treated NiTi alloys - a review. Int Endod J 51(10):1088-1103

\section{Publisher's Note}

Springer Nature remains neutral with regard to jurisdictional claims in published maps and institutional affiliations.

\section{Submit your manuscript to a SpringerOpen ${ }^{\circ}$ journal and benefit from:}

- Convenient online submission

- Rigorous peer review

- Open access: articles freely available online

- High visibility within the field

- Retaining the copyright to your article

Submit your next manuscript at $\boldsymbol{\nabla}$ springeropen.com 